\title{
¿Derecho a la vivienda o la propiedad privada? De la política pública a la informalidad urbana en el Área Metropolitana de Lima (1996-2015)
}

Diana Torres. Universidad Peruana de Ciencias Aplicadas, Lima, Perú. Javier Ruiz-Tagle. Pontificia Universidad Católica de Chile, Santiago, Chile.

RESUMEN | Como consecuencia de la política de titulación masiva ejecutada por el gobierno peruano desde 1996, miles de peruanos se han convertido en propietarios individuales de la tierra, pero la obtención de la titularidad no ha avanzado simultáneamente con la obtención de la habitabilidad urbana. Se presenta un estudio de caso de los barrios resultantes de esta forma de producción de suelo urbano en el Área Metropolitana de Lima, poniendo en evidencia que la organización social es la que se encarga de lograr la consolidación urbana, sustituyendo la función del Estado en esta área. Se concluye que la política ha inducido en las organizaciones sociales la valoración del bien privado por sobre la lucha colectiva en la construcción del hábitat urbano, lucha que se ve no solo obturada, sino también detenida. Esta situación es reforzada constantemente por las instituciones estatales y los efectos de la restructuración económica del país.

PALABRAS CLAVE | periferia urbana, asentamientos humanos, política urbana.

ABSTRACT $\mid$ As a consequence of the massive titling policy implemented by the Peruvian government from 1996, thousands of citizens have become individual landowners; but this legal ownership has not improved the minimum habitability in urban settlements. We present a case study on the neighborhoods resulting from this mode of land production in the Metropolitan Area of Lima, proving that social organization is the one actually in charge of achieving urban consolidation, replacing the role of the State. It is concluded that this policy has induced in social organizations, the valuation of the private good over the collective struggle for the construction of the urban habitat, which is not only blocked, but also stopped. This situation is constantly reinforced by state institutions and the effects of economic restructuring.

KEYWORDs | urban periphery, human settlements, urban policy. 


\section{Introducción}

Iniciado el nuevo milenio, y debido a la intensa propagación de la informalidad y pobreza urbana en Latinoamérica -y, en general, en el Sur Global-, nuevas investigaciones sobre la vivienda y la urbanización plantean que los asentamientos informales son un modo generalizado de urbanización metropolitana y no solo la excepción a la lógica de la planificación tradicional. En el caso peruano, el país ha tenido un crecimiento económico sostenido en la última década, dejando su condición de país pobre. En Lima, la reducción de la pobreza se ha visto reflejada en la emergencia de una nueva clase media. Sin embargo, esta exaltación de la economía en ascenso no se condice con la realidad de la producción del suelo urbano y sus condiciones en términos de calidad de vivienda, infraestructura, equipamiento y espacio público, por citar algunos aspectos básicos.

La informalidad urbana en Lima, y en el Perú, es un fenómeno que tiene larga data, y que influenció el desarrollo del debate académico y político sobre la informalidad urbana desde 1961. Ese año el Estado promulgó la Ley de Barrios Marginales, reconociendo la existencia de asentamientos informales y la importancia de su legalización. Fue una normativa pionera en Latinoamérica. Siempre con énfasis en Lima, comenzó un proceso de saneamiento físico y legal. A partir de 1968 se modificó la mencionada ley y se privilegió la seguridad de la tenencia jurídica por sobre la provisión de servicios básicos e infraestructura, debido a los altos costos que esta última representaba para el Estado. Tal situación se mantuvo en la década de 1980, cuando el país sufrió una profunda crisis económica por la hiperinflación y una crisis social debido a los conflictos armados internos generados por Sendero Luminoso.

En 1990, Alberto Fujimori asumió el gobierno y realizó reformas radicales, principalmente económicas, lo que se tradujo en el incremento de la pobreza e indigencia y la profundización de la inequidad social y económica, amplificando así el fenómeno de la informalidad urbana en el país, y en especial en Lima. Se eliminaron, además, todas las políticas de planificación urbana y de vivienda (Calderón, 2016). Fujimori, bajo el asesoramiento intelectual de Hernando de Soto y el financiamiento del Banco Mundial, creó en 1996 la Comisión Nacional de Formalización de la Propiedad Informal (Cofopri), presentándola como el organismo que cambiaría el paradigma de la informalidad urbana en el Perú y contribuiría a erradicar la pobreza. Sin embargo, sus funciones continuaron acotadas a la entrega de títulos de dominio, y se omitió el acceso a la vivienda y la habilitación urbana. Desde entonces, el fenómeno de la informalidad urbana se ha agudizado y convertido en el principal modo de crecimiento de la ciudad, configurando un espacio urbano de distintos niveles de consolidación e integración a la estructura urbana de la ciudad formal. En la actualidad, el 54\% del Área Metropolitana de Lima (AML) está ocupada por asentamientos informales (Torres, 2016), conocidos en el Perú como asentamientos humanos (AAHH). Según el último censo oficial $(2007),{ }^{1}$ en estas zonas vive el $49 \%$ de la población de Lima.

1 Aunque el último registro oficial realizado en el Perú es el xII Censo de Población, vir de Vivienda y III de Comunidades Indígenas o Censo peruano de 2017, el Censo Nacional 2007: xI de Población y vi de Vivienda, es aquel al que se tuvo acceso al escribir el artículo. 
Investigadores nacionales y extranjeros han publicado numerosos estudios que demuestran el fracaso de la Cofopri en términos de incorporar la población al mercado económico formal a través de créditos hipotecarios, tal como planteaba inicialmente Hernando de Soto. Asimismo, se señala que ha contribuido al incremento del tráfico de tierras, por la simplificación de trámites en la obtención de títulos de dominio. Pero poco se ha estudiado respecto de la relación entre la producción social de suelo urbano informal y los actores que se disputan el poder dentro del mismo. En esa línea temática, mediante un estudio de casos, este artículo investiga qué efectos ha tenido la Política Nacional de Formalización (PNF, ejecutada por la Cofopri) sobre la organización social. Catastrados individualmente, miles de residentes se han convertido en propietarios individuales de la tierra, pero la obtención de la titularidad no ha avanzado simultáneamente con el logro de habitabilidad urbana.

En las siguientes secciones se presentará el debate teórico sobre la informalidad urbana, su relación con el rol del Estado frente al hábitat popular, y el capital social en términos de organización social en un contexto neoliberal. Seguidamente se presentan los casos de estudio y se discuten los resultados bajo tres temáticas: la producción del espacio urbano en el AML, las consecuencias de la PNF y el rol de la organización social como promotor urbano. Finalmente, se concluye comentando los principales hallazgos y las implicancias para las políticas urbanas.

\section{Aproximaciones teóricas}

Brenner y Schmid (2014) sostienen, en el campo del desarrollo urbano extendido y cada vez más universal, que "las aglomeraciones se forman, expanden, contraen y transforman de manera continua, pero siempre a través de densas redes de relaciones con otros lugares, territorios y escalas, incluidos los ámbitos tradicionalmente clasificados como ajenos a la condición urbana” (p. 61). En el Sur Global, esta tendencia está claramente ejemplificada en el fenómeno de la informalidad urbana, entendida en todas sus dimensiones como un modo de urbanización que la planificación urbana debiera tratar de resolver a distintas escalas de gestión y de replantearse sus dilemas prácticos (Porter, 2011), pues remece las bases epistemológicas de la planificación.

Roy y Alsayyad (2004) presentan una compilación de ensayos sobre la informalidad urbana asociada a los asentamientos humanos en diferentes geografías (Medio Oriente, África, Latinoamérica y el Sudeste Asiático), como un modo generalizado de urbanización metropolitana y no como una excepción a la lógica de la planificación. Sus contribuciones revelan que los asentamientos informales dejaron de ser un dominio exclusivo de los pobres urbanos, y que se han convertido en una importante zona de operaciones para la clase media -e incluso para elites transnacionales-, que genera nuevas formas de poder social y político para el uso del espacio. Argumentan también que la informalidad urbana ha devenido "un modo de vida" en un contexto neoliberal, pues la diferencia ya no está entre la formalidad y la informalidad, sino en la diferenciación y variedad de formas que existen dentro de la informalidad, lo cual delimita los diferentes tipos de acumulación dependiendo del 
grupo poblacional que genere esta informalidad. La cuestión, entonces, es que, en la actualidad, la informalidad urbana se reproduce en medio de un complejo sistema de "intereses de propiedad" existentes. Por lo tanto, el enfoque de la seguridad de la tenencia validado por los derechos de la propiedad individual, que era el fin último de los programas de formalización en los sectores informales, se ha traducido "en el derecho de participar en los mercados inmobiliarios" (Roy, 2005, p .152).

La informalidad urbana se vuelve compatible con mercados de suelos, pues ambas modalidades coexisten geográficamente formando una estructura interdependiente, generando lo que en Latinoamérica se conoce genéricamente como "mafia de tierras". Fernandes (2008) explica que, en términos relativos, "los habitantes de asentamientos informales pagan precios absurdos para vivir en condiciones extremadamente precarias. Se ha creado toda una industria alrededor de la producción informal de la ciudad, que no se relaciona únicamente con el aumento de la pobreza" (p. 29). La reglamentación urbana, el régimen jurídico-legal y la planificación urbana de las ciudades operan de modo excluyente. La negación de esta realidad la exacerba. Jaramillo (2008) propone que, además de estos costos monetarios (respecto a infraestructura, abastecimiento de agua, etcétera), muy altos para los pobres, existen costos no monetarios, como la seguridad personal y la agilización de trámites de obtención del terreno, que son los que compensan los costos monetarios que los residentes están dispuestos a solventar.

Para Jaramillo (2008), existen "agentes capitalistas informales" que se aprovechan de esta situación, y bajo la modalidad del loteo pirata abastecen el mercado informal de la tierra, como una alternativa a los altos costos no monetarios que trae consigo la invasión tradicional. De este modo, el "urbanizador pirata" se convierte en el agente capitalista del mercado informal de la tierra, que captura los aumentos de precios, delimita lotes y hasta maneja la organización de residentes para lograr el abastecimiento de servicios del Estado. Se deduce, entonces, que la ciudad popular latinoamericana se produce a partir de una lógica informal, se habita de modo ilegal y se construye de modo irregular. Sin embargo, sería injusto culpar solo a los residentes. La continuidad de este círculo vicioso se debe a la irracionalidad administrativa y a la mala práctica de algunos funcionarios públicos, que generan mecanismos de clientelismo traducidos en altos costos de dotación de servicios y equipamientos (Clichevsky, 2003). El rol del Estado en la política económica, social y habitacional no ha tenido una base sólida, especialmente en Perú. Por el contario, con el devenir de los años se han gestado muchos debates sobre cuál sería el rol más apropiado. Para Gilbert (2001), el debate tiene su origen en la década de 1950, cuando se pensaba que la mayor causa del subdesarrollo en América Latina radicaba en fallas del mercado. Llegada la década de 1980, la culpa se transfirió al gobierno, por su incapacidad de dar soluciones preventivas y centrarse solo en las paliativas. También señala Gilbert que en la actualidad el debate se ha equilibrado, aceptando que el mercado y el Estado tienen su propio rol, pero que falta encontrar un equilibrio entre ellos.

En cuanto a la relación entre el Estado y el hábitat popular (y, específicamente, la informalidad), se puede decir que ella responde a las características específicas de cada país y al momento histórico. Es difícil generalizar las relaciones. 
Clichevsky (2009) expone que "los gobiernos han reprimido, tolerado, admitido o propiciado las ocupaciones de tierras y construcciones, según las coyunturas políticas. Resulta difícil resumir, pues, la actitud estatal hacia las ocupaciones directas a través de la simple dicotomía tolerancia/represión" (p. 69). Sin embargo, el común denominador de los estados latinoamericanos es que el acceso a la vivienda no ha sido admitido como un problema social (Gilbert, 2001). Es decir, un desempeño cuestionable, pero perenne. De manera general, en Latinoamérica, desde 1990, el nuevo enfoque del rol estatal frente al desarrollo urbano y a la dotación de vivienda responde a un enfoque neoliberal, mercantilista e individualista. Por esta razón, la Nueva Agenda Urbana se propone reestablecer la "función social del suelo urbano", que en muchos países de Latinoamérica se desconoció con el tránsito hacia el neoliberalismo. ${ }^{2}$

Las políticas neoliberales aplicadas por la mayoría de los estados latinoamericanos -entre ellas, los programas de regularización masiva, traducidos en esquemas de privatización- "han promovido una interpretación individualista y tradicional de los derechos de propiedad, que dificulta los intentos progresistas de disciplinar el uso y desarrollo de la propiedad urbana” (Fernandes, 1999, p. 82). Se trata, según el mismo Fernandes, "de una paradoja entre una definición más progresista de los derechos de propiedad y la tendencia actual en pro de la privatización” (p. 82). La pregunta central es si estas tendencias pueden conciliarse hasta cierto punto, para lograr un mayor beneficio común.

La privatización de los derechos de propiedad tiene también una implicancia social, pues le quita importancia al rol que históricamente ha tenido la organización social en el proceso de producción de la vivienda y el espacio urbano emergente en Latinoamérica. Pero, ¿qué es lo que se espera de esta organización social? Durston (2003) y Atria (2003) resumen la importancia de la valoración de las redes de organización social o la teoría del capital social como estrategias para la superación de la pobreza y de integración de sectores sociales excluidos. Empoderar a las organizaciones sociales, creando sinergia entre la comunidad y el poder estatal en su representación más próxima -vale decir, las instancias municipales y regionales-, obliga a revisar en profundidad el rol del Estado desde su enfoque político y su decisión técnica. Debe considerarse al respecto que en los barrios informales de Latinoamérica y el Caribe las comunidades no son homogéneas -ni económica, ni culturalmente-, sino colectividades plurales, pero con una serie de necesidades e intereses compartidos. La proximidad residencial y una cierta dependencia de determinados recursos compartidos, como el acceso a redes de servicios básicos, hacen del barrio un espacio urbano especialmente propicio para desarrollar experiencias de gestión colectiva. La cohesión social generada por los 'vínculos fuertes', en la mayoría de los casos, es un factor que puede contribuir a originar capital social comunitario.

En contraposición a esta postura, Miraftab (2009) critica el enfoque de la participación ciudadana en la producción del espacio urbano, sobre todo en las áreas

La Nueva Agenda Urbana, aprobada en la Conferencia de las Naciones Unidas sobre la Vivienda y el Desarrollo Urbano Sostenible (Hábitat III) celebrada en Quito, Ecuador (2016), puede ser descargada de http://habitat3.org/wp-content/uploads/NUA-Spanish.pdf. 
informales del Sur Global. Propone que las prácticas de la "planificación inclusiva”, como la participación comunitaria impulsada por las agencias internacionales, buscan la hegemonía de la gobernanza neoliberal, extendiendo el control estatal hacia las organizaciones sociales de base y despolitizando sus luchas. Además, muchas veces se criminaliza a los movimientos sociales que militan en la izquierda. Mayer (2003) agrega que bajo los términos de la "reducción de la desigualdad" y la "inclusión social", las agencias internacionales han favorecido las relaciones de dependencia de los sectores más pobres durante las últimas dos décadas. Así, señala que los programas están más preocupados de trabajar con los pobres, que de hacerle frente a la pobreza. Para Miraftab (2009), la existencia de asentamientos informales, no solo en Latinoamérica sino en todo el Sur Global, permite a los Estados coaccionar a los residentes a cambio de la dotación de servicios básicos y de entregarles títulos de dominio, generando así lazos clientelares. De esta manera se naturalizan las políticas individualistas neoliberales, donde la propiedad privada se establece como un orden prioritario.

Finalmente, Roy (2011) y Miraftab (2009) proponen que para el logro efectivo de los derechos de ciudadanía en distintas escalas, se debe empoderar a los movimientos sociales independientes. Es decir, trabajar el capital social existente de manera responsable y sin lazos clientelares, lo que no significa disminuir la responsabilidad del Estado, sino más bien involucrarlo. Esto se debe traducir en entender las particularidades de las ciudades del Sur Global, "descolonizar" el ideal de planificación urbana formal heredada del Norte Global, y trabajar la "planificación insurgente" (Miraftab, 2009), desde abajo, desde la gente y la comunidad. Las demandas de los movimientos insurgentes cuestionan estos discursos y sus programas asociados, así como las relaciones de poder opresivas y sus respectivas ideologías.

\section{Aproximaciones metodológicas}

Para esta investigación solo se ha considerado el Área Metropolitana de Lima (AML), conformada por 43 distritos, debido a las diferencias de las gestiones locales y la existencia de información pública disponible de la Comisión Nacional de Formalización de la Propiedad Informal (Cofopri), que podrían afectar los resultados. Esto, a pesar de la conurbación y la relación de interdependencia de la Provincia de Lima y la Provincia Constitucional del Callao. En el AML se caracterizaron dos tipos de áreas de crecimiento informal: el área formalizada con títulos de dominio y el área en proceso de formalización y/o informal. El catastro de Cofopri (2016) registra 3.180 AAHH formalizados desde 1996 hasta 2015 en el AML. Sin embargo, este número puede ser menor debido a que en el trabajo de campo se registró que muchos de los AAHH formados en las décadas de 1965-1980 ya poseían títulos de propiedad otorgados por la Municipalidad Metropolitana de Lima (MML). En cuanto a los AAHH en proceso de formalización, la MML (2015) registra 1.106 AAHH con informe de riesgo -en proceso avanzado de formalización- y 47 AAHH con levantamiento de campo (reconocimiento geográfico y social del territorio ocupado), que están iniciando el proceso de formalización (figura 1). En cuanto a los AAHH informales, no se tienen datos que permitan establecer cuántos son, pero hemos estimado que en Lima Metropolitana ocupan un aproximado del 54\% del territorio urbano. 
FIGURA I | Distribución de los Asentamientos Humanos en el Área Metropolitana de Lima por macrozona

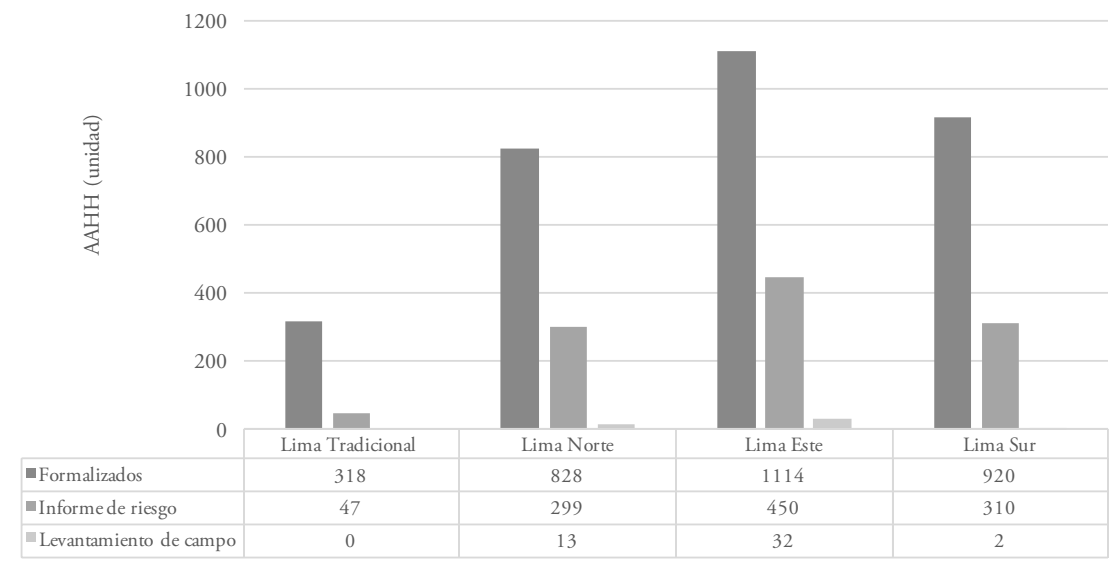

FUENTE ELABORACIÓN PROPIA CON BASE EN COFOPRI (2OI6) Y MML (20I5)

Esta investigación adopta una metodología mixta. En una primera etapa cuantitativa, mediante la utilización de un software de información geográfica (sIG), se unió la base de datos del Censo 2007, de Cofopri 2016 (3.520 AAHH formalizados) y la Encuesta sobre Situación de los Barrios Urbano-Marginales (Esbum) 2012 (148 AAHн formalizados, tomados como muestra para la encuesta, véase tabla 1). De esta manera, el análisis relacional de los datos sirvió para elaborar un Índice de Consolidación Urbana (ICU) para elegir los casos de estudio, puesto que no se contaba con una base de datos oficial que permitiera medir el grado de consolidación urbana de los asentamientos ya formalizados.

El mencionado ICU pondera tres aspectos y se calculó con la siguiente fórmula:

$$
\mathrm{ICU}=\left[\left(\mathrm{DU}^{*} 3\right)+\left(\mathrm{T}^{*} 2\right)+\left(\mathrm{TF}^{*} \mathrm{I}\right)\right] / 6
$$

donde:

- Du (grado de Desarrollo Urbano): se le pondera con valor 3, debido a que mide el grado de consolidación urbana del asentamiento, factor importante que relaciona el éxito de la Política Nacional de Formalización (PNF) con el desarrollo urbano del asentamiento (tabla 2).

- $\quad \mathrm{T}$ (tamaño del asentamiento): se le pondera con valor 2, debido a que el nivel de gestión y construcción de infraestructura para un asentamiento de mayor tamaño toma más tiempo y recursos que para uno de tamaño mediano o pequeño (tabla 3).

- TF (tiempo de formalización): medido en años, refleja el tiempo que le toma a la organización vecinal lograr la consolidación urbana. Como es un factor relativo a las condiciones políticas y organizativas, tanto del Estado como del asentamiento, se le pondera con valor 1 . 
TABla I | Fuentes de datos

\begin{tabular}{|l|l|l|l|}
\hline \multicolumn{1}{|c|}{ FUENTE } & ABREVIATURA & \multicolumn{1}{|c|}{ UTILIDAD } & \multicolumn{1}{|c|}{$\begin{array}{l}\text { NIVEL DE } \\
\text { ANÁLISIS }\end{array}$} \\
\hline $\begin{array}{l}\text { Censo Nacional de } \\
\text { Población y Vivienda 2007 }\end{array}$ & Censo 2007 & $\begin{array}{l}\text { Cuantificación y ubicación de los AAHH, } \\
\text { y caracterización demográfica y socioe- } \\
\text { conómica de la población y estado de la } \\
\text { vivienda. }\end{array}$ & $\begin{array}{l}\text { Escala } \\
\text { distrital }\end{array}$ \\
\hline $\begin{array}{l}\text { Base de datos de la Cofopri, } \\
\text { actualización al 2016. }\end{array}$ & Cofopri 2016 & $\begin{array}{l}\text { Identificación de localización y estado de } \\
\text { formalidad de los AAHH. }\end{array}$ & $\begin{array}{l}\text { Escala barrial } \\
\text { (AAHH) }\end{array}$ \\
\hline $\begin{array}{l}\text { II Encuesta Situación de los } \\
\text { Barrios Urbano-Marginales } \\
\text { 2012. }\end{array}$ & Esbum 2012 & $\begin{array}{l}\text { Identificación de las características físicas y } \\
\text { de habitabilidad de los AAHH. }\end{array}$ & $\begin{array}{l}\text { Escala barrial } \\
\text { (AAHH) }\end{array}$ \\
\hline $\begin{array}{l}\text { Base de datos de la Muni- } \\
\text { cipalidad Metropolitana de } \\
\text { Lima, actualización al 2015. }\end{array}$ & MML 2015 & $\begin{array}{l}\text { Identificación de los AAHH en proceso de } \\
\text { formalización y sus características físicas y } \\
\text { de habitabilidad según el informe de riesgo. }\end{array}$ & $\begin{array}{l}\text { Escala barrial } \\
\text { (AAHH) }\end{array}$ \\
\hline
\end{tabular}

FUENTE ELABORACIÓN PROPIA, A PARTIR DE:

(I) INSTITUTO NACIONAL DE ESTADíSTICA E INFORMÁtica (2007). CENSOS NACIONALES 2007: XI DE POBLACIÓN Y VI VIVIENDA, ENTREgados POR LEY DE TRANSPARENCIA, A SOLICITUd DE LOS INVESTIGADORES.

(II) ORGANISMO DE FORMALIZACIÓN DE LA PROPIEDAD INFORMAL (COFOPRI), BASE DE DATOS, A 20 I6, ENTREGADOS POR LEY DE TRANSPARENCIA, A SOlICITUD DE LOS INVESTIGADORES.

(III) MINISTERIO DE VIVIENDA, CONSTRUCCIÓN Y SANEAMIENTO (MVCS), DIRECCiÓN NACIONAL DE URBANISMO (DNU). (2OI2). SITUACIÓN DE LOS BARRIOS URBANO-MARGINALES EN EL PERÚ 2012. SEGUNDA APROXIMACIÓN. LIMA: MVCS.

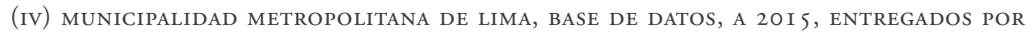
LEY DE TRANSPARENCIA, A SOLICITUD DE LOS INVESTIGADORES.

TABla 2 Grado de desarrollo urbano de los Asentamientos Humanos formalizados en el Área Metropolitana de Lima

\begin{tabular}{|c|c|c|c|c|}
\hline PUNTAJE* & $\begin{array}{l}\text { ABASTECIMIENTO } \\
\text { DE AGUA }\end{array}$ & $\begin{array}{c}\text { ABASTECIMIENTO } \\
\text { DE DESAGÜE }\end{array}$ & $\begin{array}{l}\text { ABASTECIMIENTO } \\
\text { DE LUZ }\end{array}$ & ACCESOS \\
\hline 3 & Medidor individual & Medidor individual & Medidor individual & Vías asfaltadas \\
\hline 2 & Conexión colectiva & Conexión colectiva & Conexión colectiva & Vías compactadas \\
\hline 1 & $\begin{array}{l}\text { Camión cisterna, pilón } \\
\text { de uso público, o pozo }\end{array}$ & Pozo séptico & $\begin{array}{l}\text { Conexión } \\
\text { clandestina }\end{array}$ & $\begin{array}{l}\text { Vías de superficie } \\
\text { múltiple }\end{array}$ \\
\hline 0 & Río o similar & Letrina & Sin abastecimiento & Solo peatonal \\
\hline FUENTE & \multicolumn{4}{|c|}{$\begin{array}{l}\text { LOS VALORES Y LA CARACTERIZACIÓN DE SERVICIOS SE HAN REALIZADO DE ACUERDO CON LC } \\
\text { OBSERVADO EN EL TRABAJO DE CAMPO. }\end{array}$} \\
\hline
\end{tabular}

TABLA 3 | Tamaño de los Asentamientos Humanos formalizados en el Área Metropolitana de Lima

\begin{tabular}{|l|c|c|}
\hline \multicolumn{1}{|c|}{ TAMAÑo* $^{*}$} & RANGO (CANTIDAD DE LOTES) & PUNTAJE \\
\hline Pequeño & $1-200$ & 1 \\
\hline Mediano & $201-800$ & 2 \\
\hline Grande & 801 o más & 3 \\
\hline
\end{tabular}

(*) LA CARACTERIZACIÓN SE BASA EN LOS PROYECTOS REALIZADOS POR EL PROGRAMA “MI BARRIO” DEL MINISTERIO DE VIVIENDA, CONSTRUCCIÓN Y SANEAMIENTO (MVCS, 2006); Y “BARRIO MÍO” DE LA MML (2OI 2-2OI4). EL PRIMERO REALIZABA INTERVENCIONES EN AAHH PEQUEÑOS (ENTRE $200 \mathrm{Y} 300$ LOTES), Y EL SEGUNDO EN AAHH GRANDES (ENTRE 800 Y IOOO LOTES).

FUENTE ELABORACIÓN PROPIA 
El ICU solo se aplicó a los AAHH formalizados y se eligió los que poseían mayor grado de consolidación, bajo el supuesto de que si se analizaban los casos más exitosos se podía inferir cuál es el estado de los de menos puntaje y analizar el impacto directo de la PNF en la consolidación urbana. Se escogieron dos AAHH por macrozona: Lima Norte (аAн 9 de Setiembre у аАнн 19 de Mayo), Lima Este (аAнH La Providencia у ААнн Villa Huanta) y Lima Sur (AAнH Luis Felipe de las Casas Grieve I y aAHH Mártires de San Juan), para así tener un panorama global del AML (figura 2).

FIGURA 2 Ubicación de los casos de estudio

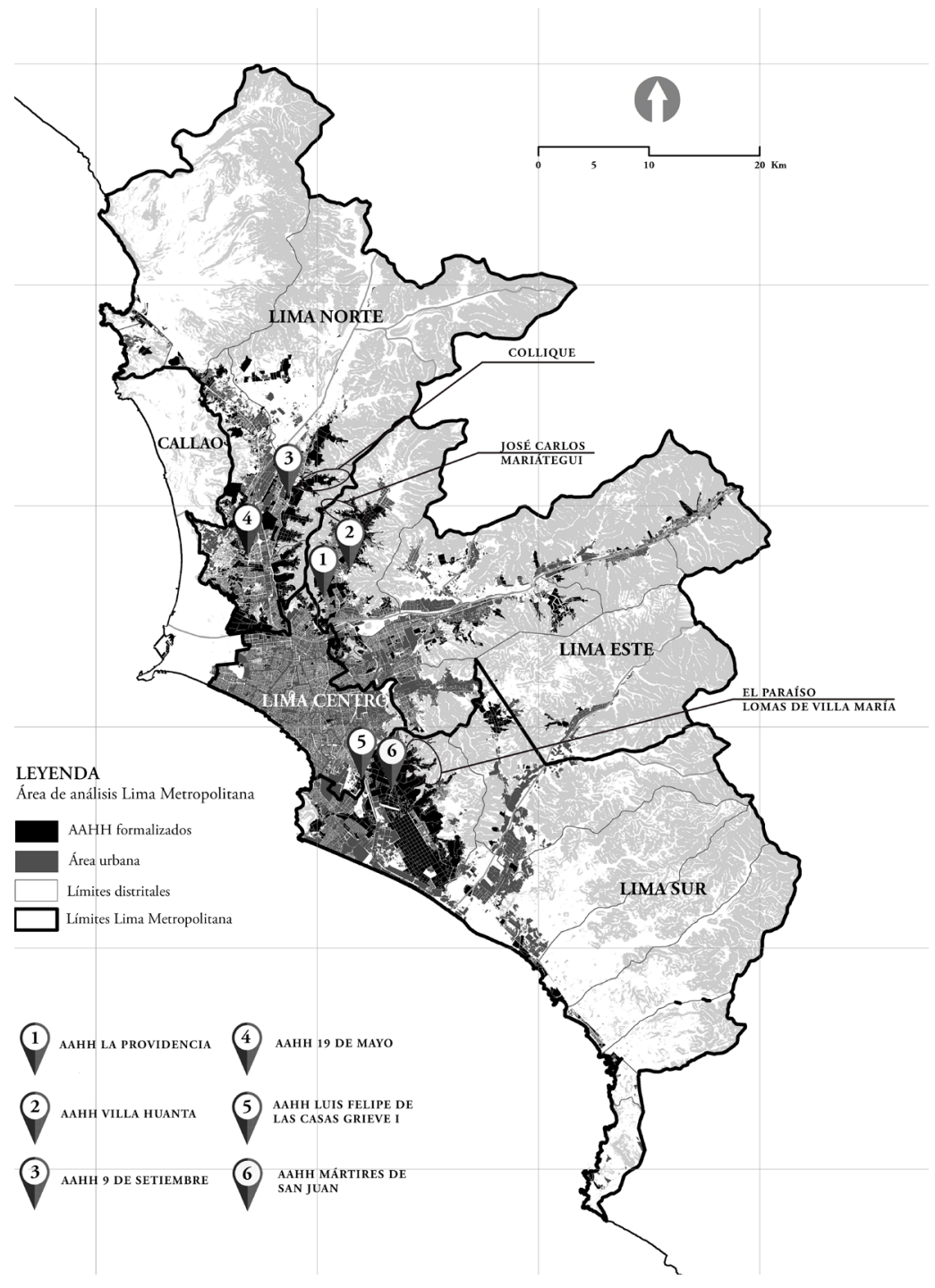

FUENTE ELABORACIÓN PROPIA CON BASE EN MATOS (2OI2) y COFOPRI (2OI6) 
En una segunda etapa se aplicó una metodología cualitativa en el trabajo de campo. Se elaboró una ficha de observación para obtener información descriptiva de cada AAHH, como complemento a la caracterización de los datos obtenidos con la estrategia cuantitativa. Luego se realizaron treinta entrevistas en profundidad a informantes clave: dirigentes, exdirigentes y residentes de los asentamientos que se tomaron como casos de estudio. En paralelo al trabajo de campo, se revisaron documentos y/o archivos periodísticos e históricos como complemento al relato de los informantes. Adicionalmente, se realizaron entrevistas semiestructuradas a actores clave en el proceso administrativo de formalización, para entender las distintas visiones políticas y de gestión: directivos del MvCs, directivos y personal técnico de Cofopri, personal técnico de la mML en la gerencia de Desarrollo Urbano, e investigadores académicos y consultores reconocidos en el campo de los estudios urbanos en el Perú.

En cuanto a los asentamientos no formalizados e informales, se realizaron conversaciones de carácter etnográfico en las zonas de Collique (Comas) al norte, José Carlos Mariátegui (San Juan de Lurigancho) al este, y El Paraíso y Lomas de Villa María del Triunfo al sur. Se recurrió a esa modalidad debido al temor de los residentes a dar una entrevista formal, pues pensaban que se podía afectar su proceso de formalización y podían ser criminalizados por la invasión de los terrenos (figura 2).

\section{Casos de estudio}

La característica general de los AAHH tomados como casos de estudio (tabla 1) es la no correspondencia entre los datos de titulación entregados por Cofopri con el tiempo de la tenencia del título de propiedad. En todos los casos los residentes ya habían recibido, muchos años antes de la creación de la Cofopri, el título de propiedad otorgado por la Municipalidad Metropolitana de Lima. En cuanto al grado de consolidación urbana, todos los AAHH estudiados cuentan con los servicios básicos (agua, alcantarillado y luz) aunque en distintos niveles de abastecimiento. Respecto al entorno urbano, los seis AAHH tienen pistas de acceso y vías secundarias asfaltadas (entre el $80 \%$ y $100 \%$ ). Sin embargo, no en todos ellos se han construido veredas -el promedio varía del $40 \%$ al $50 \%$-, lo que dificulta la movilidad peatonal. En cuanto al equipamiento comunal, los seis AAHH presentan algún tipo de espacio comunal para desarrollar actividades que motivan la vida del barrio. Las más destacadas son lozas deportivas, parques y capillas.

En cinco de los seis AAHH existe organización vecinal, representada por la Junta de Vecinos. Aunque el nivel de participación está entre bajo y medio (según la etapa en el proceso de formalización y los requerimientos para superar el riesgo, véase tabla 4), todavía existen elecciones y se reúnen para seguir trabajando en la mejora del barrio. Al respecto, todos los vecinos hacen referencia a la poca ayuda recibida por el Estado.

En los AAHH informales se observó que casi la totalidad enfrenta con intensidad el problema del tráfico de tierras. Debido a esta situación, la inseguridad para los visitantes ha aumentado, pues los traficantes de tierras incluso están armados y 
presentan una actitud muy hostil hacia el visitante. Sobre la organización vecinal, siguen vigentes las directivas vecinales, con el único objetivo de lograr la seguridad de la tenencia. Como se señaló arriba, el grado de participación varía de acuerdo con la etapa en que se encuentren el proceso de formalización y las exigencias de su Informe de Riesgo. ${ }^{3}$ Mientras más requerimientos tengan para superar el riesgo, se dice que existe una mayor participación vecinal. En este sentido, se verifica que el grado de riesgo asociado a estos asentamientos es alto respecto a los asentamientos formalizados. En cuanto a los Informes de Riesgo, se evidencia que sirven como un mecanismo clientelar, puesto que en los años de finalización de periodos gubernamentales estatales $(2006,2010)$ se emite un gran número de ellos (figura 3) para fidelizar los votos.

3 El Informe de Riesgo es un documento técnico emitido por el Instituto Nacional de Defensa Civil del Perú (Indeci). Su finalidad es caracterizar el grado de consolidación urbana, y la vulnerabilidad asociada, de todo asentamiento humano en proceso de formalización de la tenencia del suelo. 


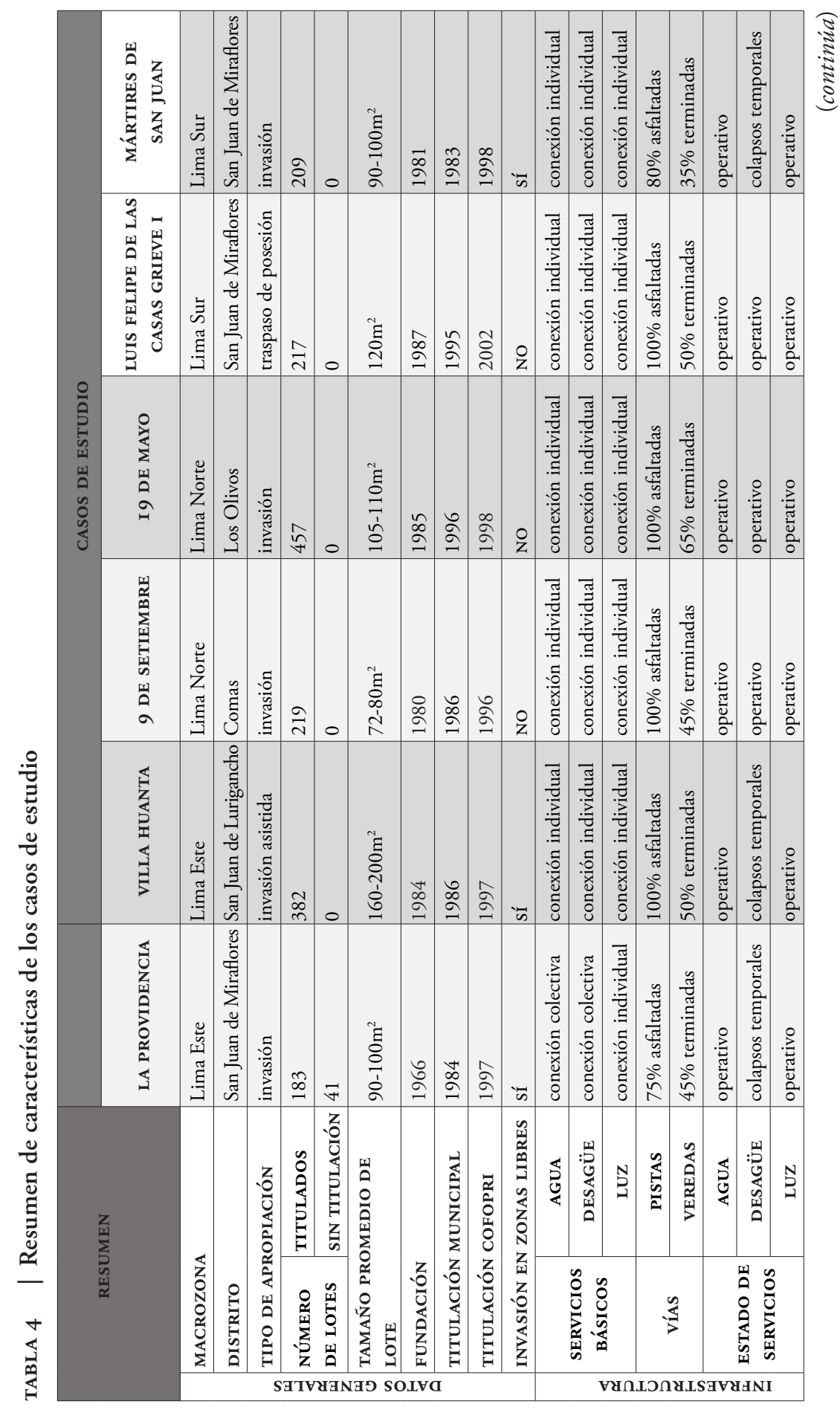




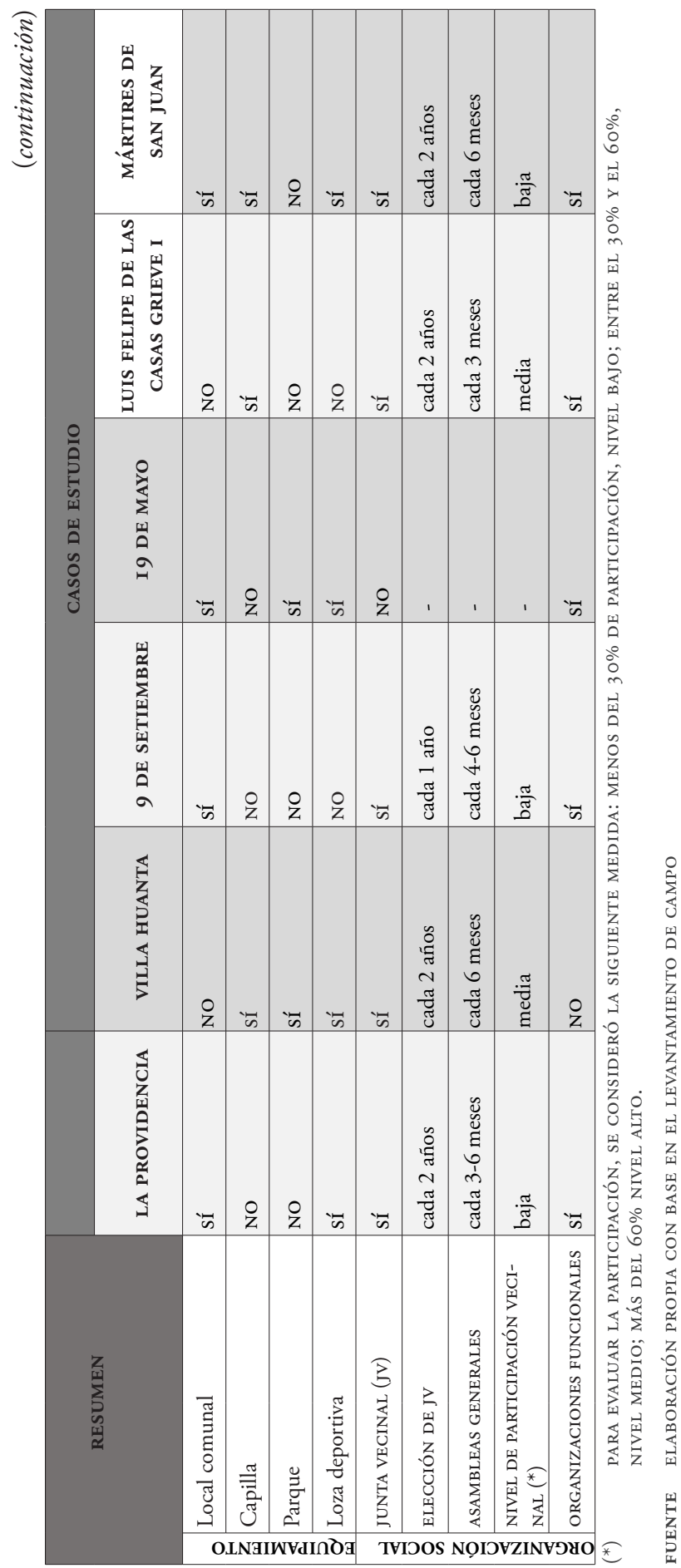


FIGURA 3 | Número de Asentamientos Humanos no formalizados con emisión de Informes de Riesgo por ańo

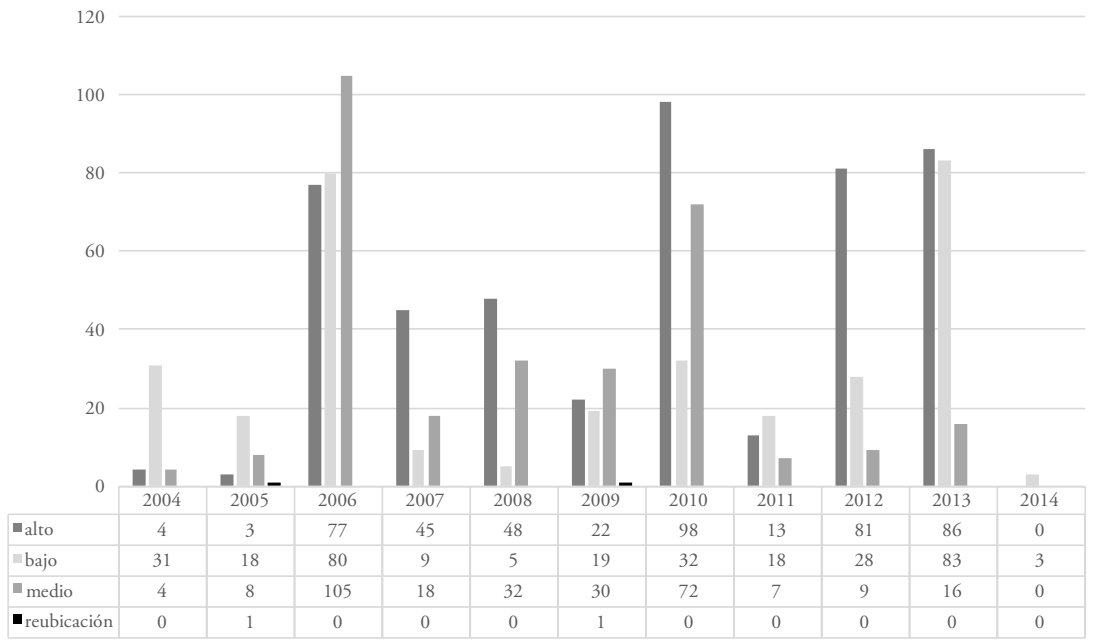

FUENTE ELABORACIÓN CON PROPIA CON BASE EN MUNICIPALIDAD METROPOLITANA DE LIMA (2OI5)

\section{Producción del espacio urbano en Lima: entre la planificación y la urbanización popular}

La condición urbana de Lima es el resultado del proceso de urbanización popular, cuya lógica de organización comenzó siendo muy ordenada. Con el paso del tiempo, sin embargo, la lógica fue tornándose cada vez más caótica. En la actualidad, la informalidad es un estado generalizado en todo el AML, sobre todo en las áreas donde se ubican los AAHH, pues sus residentes viven y producen económicamente bajo un sistema informal, aduciendo que los costos de ser formal rebasan sus capacidades de ganancia. Además, al no existir un plan de desarrollo urbano para Lima, los mecanismos de regulación urbana pierden vigencia, quedando la planificación urbana sujeta a la visión del alcalde de turno. La ciudad de Lima se ha pensado poco, pero en ella se ha construido mucho. En el trabajo de campo se han detectado varios tipos de informalidad urbana, tanto en los asentamientos formalizados como en los asentamientos no formalizados e informales, los que han sido caracterizados de acuerdo con las definiciones de Viana (2007).

En los asentamientos formalizados se evidencia la irregularidad constructiva, en primer orden, pues pese a existir la tenencia legal del suelo, lo que se construye sobre el lote no se ajusta a una regulación ni técnica ni administrativa. En segundo orden, se evidencia la irregularidad del mercado inmobiliario, puesto que la mayoría de las transferencias de compraventa no se inscriben en los Registros Públicos, por lo que los participante en ellas están propensos a juicios por sucesión de bienes.

En cuanto a los asentamientos no formalizados e informales, la ilegalidad de la tenencia es la más generalizada. A pesar de que los AAHH no formalizados tienen una 
"constancia de posesión" otorgada por la municipalidad distrital correspondiente, los linderos del terreno ocupado no están definidos, ocasionando peleas internas por el área ocupada. La irregularidad urbana se presenta como un efecto directo de los asentamientos no formalizados e informales. Estos en su mayoría no cumplen con las normas urbanas para el dimensionamiento de vías; lo que ocasiona que, ante cualquier evento de emergencia, las ambulancias o bomberos no puedan ingresar al lugar. Adicionalmente, algunos asentamientos tienen una movilidad restringida al uso de las vías solo por peatones, debido a su ubicación en las partes más altas de los cerros. Por último, se evidencia la ilegalidad del mercado en las transacciones de compraventa de los lotes, que en la mayoría de los casos son realizadas ante notarios públicos. Sin embargo, a pesar de la validez de esta acción, al no ser los vendedores dueńos legales del lote en venta (no tienen título de propiedad), pueden darse muchas transacciones de compraventa en un solo lote. En el caso de las mafias de tierras, los dirigentes emiten boletas simples por la venta, sin ningún valor legal.

Explicadas las lógicas de la informalidad urbana presentes en el AML, es preciso preguntarse por los productores del espacio urbano en la ciudad. En la Lima formal, los productores del espacio urbano son el Estado y el mercado inmobiliario. En la otra Lima, la informal, la producción del espacio urbano se realiza por varios actores cuyas lógicas de apropiación del espacio varían de acuerdo con su capacidad de gestión y de recursos. En orden de intensidad de intervención, el Estado se ubica en el tercer lugar, siendo el que menos interviene como productor de espacio. En segundo orden se ubican los residentes que habitan estos asentamientos, quienes en primera instancia toman posesión del suelo por necesidad de vivienda. Su lógica de apropiación responde a esa necesidad y luchan colectivamente por dotar al espacio barrial de todas las condiciones necesarias para el bienestar futuro. $\mathrm{Y}$ en primer orden, el mayor productor de suelo urbano en la actualidad es el mercado informal del suelo, cuyo principal actor es llamado en Perú "traficante de tierras", y en la literatura latinoamericana, "urbanizador pirata".

La lógica del loteo de suelo no habitado es promovida por la permisividad del Estado como ente regulador. Muchas veces se coluden los funcionarios públicos y las personas inescrupulosas, que se posesionan de terrenos privados y estafan a los compradores. Este último productor de suelo urbano ha agotado el modelo de crecimiento por expansión iniciado en la década de 1950 con las primeras barriadas. Solo queda suelo marginal ubicado en zonas de alto riesgo natural, o con pendientes muy pronunciadas que hacen imposible la dotación de servicios y presentan graves problemas de conectividad con las zonas urbanas consolidadas.

\section{El fracaso de la Política Nacional de Formalización: del derecho a la vivienda al derecho a la propiedad privada}

El origen de la barriada tiene como antecedente el déficit de vivienda popular, sobre todo por inacción del Estado en ese ámbito. Los gobiernos peruanos siempre han apostado por hacer viviendas para la clase media, omitiendo a gran parte de la población de bajos ingresos que no podía acceder a créditos hipotecarios. Gustavo Riofrío explica que los grupos populares optan por la barriada como medio de 
obtención de vivienda debido al bajo costo de acceso, pese al alto costo de permanencia. "Por eso es importante entender la racionalidad del proceso de la creación de la barriada para entender su modificación en el tiempo", señala (Riofrío, entrevista personal, 15/04/2016).

El rol del Estado frente a la barriada se ha manifestado a través de diversas actuaciones, desde una modalidad represora a otras de planificación o regulación, dependiendo de la voluntad política del gobierno de turno -en primera instancia- y de su capacidad de gestión y recursos económicos. Cuando el Estado decidió ayudar al desarrollo del hábitat popular, siempre ha sido solo a través de propuestas paliativas, que abarcan desde la entrega de "lotes con servicio" (Ley 13517), de bonos para ayuda a la autoconstrucción (Banco de la Vivienda, Enace, Fonavi), hasta finalmente la regulación masiva del suelo con créditos para la construcción de vivienda, debido a su bajo costo de operación.

Ya que nunca se optó por dotar de viviendas construidas sino por entregar la tenencia del suelo, el área urbana en Lima -y en general en el Perú- se ha ido configurando bajo la lógica del "derecho privado absoluto", que está ampliamente regulado en el Código Civil (Riofrío, entrevista personal, 15/04/2016). Esta situación siempre fue aprovechada por los gobiernos de turno, sobre todo municipales, generando vínculos clientelares, desde partidos de izquierda y de derecha.

... en 1983, como apoyábamos a Barrantes, porque éramos de izquierda, él nos dijo que nos iba a dar título de propiedad. Que iba a ser su primer trabajo si llegaba al sillón. Y así fue, a los noventa días de iniciada su gestión, nos dio nuestros títulos...

(Durand, vecino del AaHH 9 de Setiembre).

La regulación del suelo llegó a su máximo apogeo en la década de 1990, cuando Fujimori eliminó de la Constitución en 1993 la función social del suelo y se implantó la lógica de la tenencia segura de la propiedad privada para superar la pobreza urbana, como lo plantea Hernando de Soto (1986). Esto, a pesar de que la implementación de la regulación masiva contradecía los principios de la seguridad de la tenencia, pues en algunos casos se reconoció la titulación municipal anterior y en otros se omitió. Dentro de los lineamientos de la Política Nacional de Formalización se creó el Registro Predial Urbano (RPU) para agilizar los trámites de inscripción de los títulos entregados por Cofopri. Pero los datos no estaban correctamente correlacionados con los del Registro Público, por lo que se tituló lotes con dueño ilegítimo. Julio, vecino del asentamiento 19 de Mayo, en su testimonio manifiesta que Cofopri generó un caos en el asentamiento, pues desconoció los títulos previos otorgados por la Municipalidad Metropolitana de Lima, bajo la lógica de que el dueño del lote era quien vivía en él:

...por eso los dirigentes les entregaron a sus hijos y a toda su familia los lotes, porque como no lo podía regularizar con la Municipalidad, trajeron a Cofopri y regularizó. Cofopri vino a arreglar la mafia que habían armado los dirigentes y regularizarlos...

$\mathrm{Al}$ respecto, dos de los seis casos de estudios se encuentran actualmente en litigio con los propietarios originales de los terrenos invadidos. 
Cofopri fue una institución que generaba lazos clientelares entre los AAHH y el gobierno de Fujimori, entregando títulos de propiedad en poco tiempo debido a que debían cumplir metas anuales, establecidas de acuerdo con los lineamientos que presentaron al Banco Mundial (tabla 5). En los AAHH formalizados visitados, se ha verificado que ya tenían título de propiedad anterior a la creación de la Cofopri. Sin embargo, en la base de datos aparecen como asentamientos formalizados por Cofopri. Los vecinos están al tanto de la situación, como es el caso de Wilder, del Asentamiento 12 de Agosto, que explica la función de Cofopri:

... sí vino [Cofopri], en la época de Fujimori, según ellos a verificar. Pero todo era una treta política, para decir que ellos habían dado un millón de títulos, lo que no es cierto, porque ya nosotros teníamos título otorgado por la Municipalidad de Lima, inscrito en los Registros Públicos, que es lo que vale. Lo único que actualizaron es el distrito, porque nuestro primer título salió como San Martín de Porres, pero cuando se crea Los Olivos, nos cambian. Eso fue todo lo que se actualizó...

TABLA 5 | Títulos de propiedad entregados por año y gobierno (1996-2015)

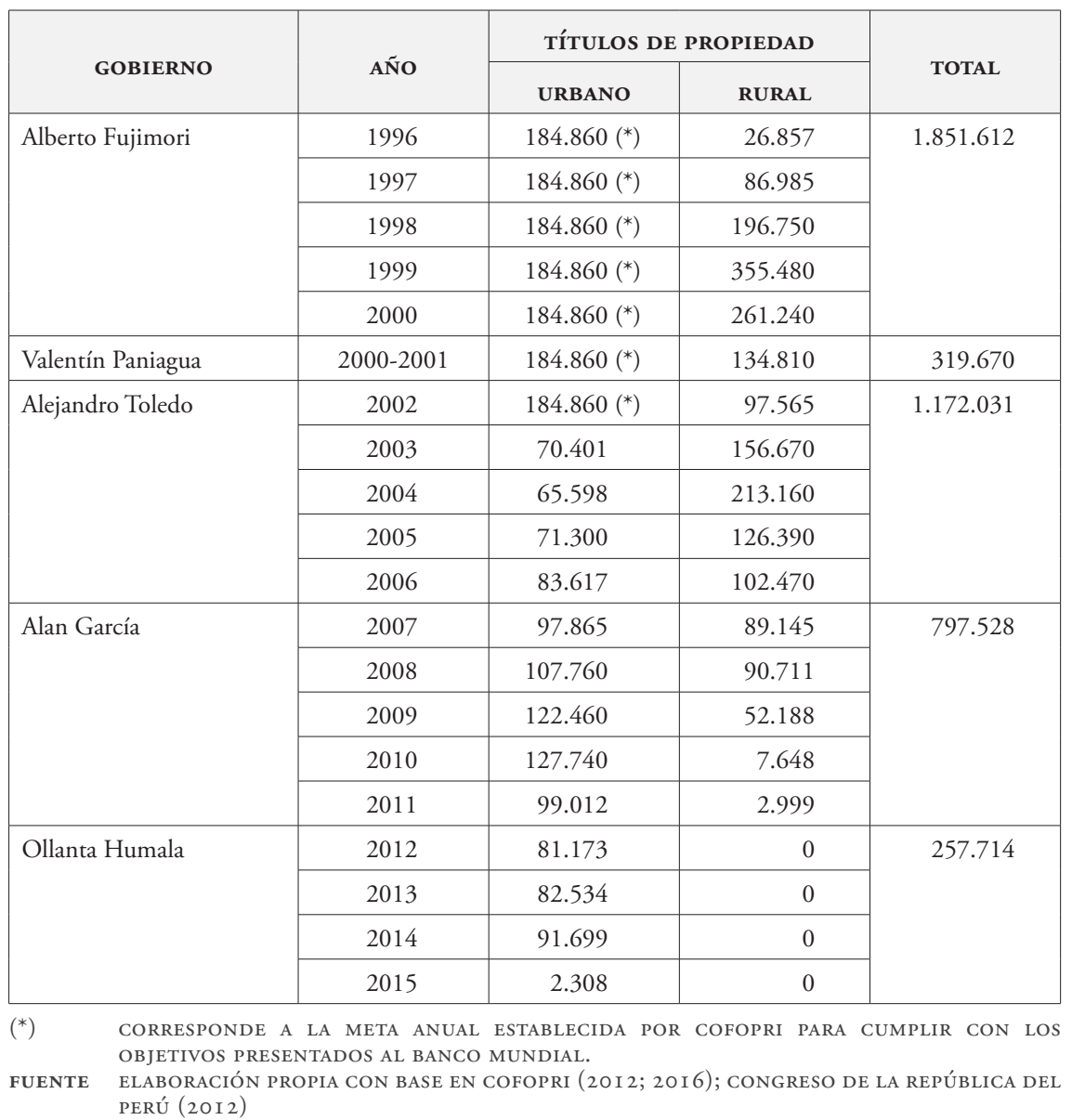


Existen actualmente en el Congreso de la República catorce pedidos de ampliación de la Ley de Saneamiento, para reconocer las invasiones de terrenos del Estado hasta 2018 (Tagle, entrevista personal, 12/04/2016), resaltando el fin político y clientelar de la PNF. Los vecinos reconocen que la voluntad política es esencial para ayudarlos a lograr la consolidación urbana de su asentamiento. Sin embargo, validan el clientelismo como una buena práctica, como señala César, habitante del Asentamiento Luis Felipe de las Casas Grieve I:

... en San Juan [de Miraflores] ha sido todo más manejable, porque no tenían pues toda la infraestructura o el sistema para poder manejarlo. Entonces, todo se pasaba por agua tibia. Gracias a Dios eso se ha dado para beneficio de todos nosotros...

En resumen, el Perú ha sido y es un Estado indulgente frente a la informalidad urbana, y sus políticas han sido solo paliativas y no preventivas. Las consecuencias de esta forma de actuar de la voluntad política, traducida a clientelismo, están generando una crisis social multisectorial, sobre todo en los ámbitos vinculados a la salud, cuyas víctimas son las personas más vulnerables: niños y ancianos. Debido a la mala calidad del agua y las condiciones de saneamiento, las enfermedades bronquiales y estomacales han aumentado exponencialmente, según los reportes anuales del Ministerio de Salud. Hoy se están evidenciando los efectos colaterales de la titulación masiva, que ha dejado de ser un problema solo de orden urbano o legal, pues afecta directamente el bienestar de la población.

\section{¿La organización social como desarrollador urbano?}

Para entender la informalidad urbana en el AML, es necesario diferenciar el tipo de residente de las primeras barriadas hasta la década de 1980, y los residentes de la década de 1990 hacia adelante. El primer grupo luchaba por obtener una vivienda, lo que Abramo (2008) llama la "lógica de la necesidad", debido a que el proceso de formalización era largo: había que hacer el saneamiento físico primero, para luego pasar al saneamiento legal (Ley 13517) y finalmente obtener el título. Los residentes de esa época luchaban por su reconocimiento colectivo ante el Estado, debido a la incapacidad de este para dotarlos de vivienda, ya que en su mayoría eran proletarios, obreros y madres solteras (Calderón, 2016). En la actualidad, los que aún residen en estas barriadas se identifican como residentes de asentamientos humanos, pero presentan un comportamiento dicotómico. Se sienten orgullosos de lo obtenido por su lucha, pero, por otro lado, una vez lograda la titularidad, discriminan a los residentes "informales" -quienes no tienen aún el título de dominio-. Hacen una marcada diferenciación de estatus, tanto laboral como conductual.

El segundo tipo de residente no obedece fundamentalmente a la lógica de la necesidad, sino a la de acumulación de patrimonio. Mayoritariamente de clase media baja, estos residentes pueden adquirir una vivienda con subsidio, pero prefieren obtener un terreno para edificar su patrimonio. Por este motivo renuncian a los beneficios de la urbanización formal, a cambio de hacerse de un título de propiedad que, en el futuro, pueda darles beneficios económicos. Esto puede ser explicado por las facilidades que entregan ahora las grandes casas comerciales para 
acceder a tarjetas de crédito y préstamos. Es decir, la financiarización de la economía no ha excluido a los sectores socioeconómicos de más bajos ingresos, sino, por el contrario, ha encontrado maneras de introducirlos a su mercado. Respecto a su identidad como residentes de un asentamiento humano, reniegan de su condición, pues frecuentan círculos sociales diversos (laborales, educativos, de recreación, etcétera) donde los residentes de AAHH son vistos como personas con menor estatus social. Claro está que aún existen residentes que no cuentan con los medios económicos para obtener una vivienda y encuentran en esta modalidad su única salida, pero representan la minoría.

Esta diferenciación de tipos de residentes explica el tipo de organización vecinal que se da en los АAнH, tanto formalizados como no formalizados. Los más antiguos presentan una organización más sólida, y aunque el grado de participación ha disminuido con el tiempo, tienen conciencia de su carácter colectivo. Por otro lado, los AAHH recientes se organizan para lograr la consolidación urbana, pero como medio para desarrollar su proyecto personal de vida y no como lucha colectiva de "construcción de ciudad". Como la PNF permitió la obtención de los títulos individuales en el corto plazo, las redes sociales no se fortalecían, mermando el grado de participación de los vecinos en las juntas vecinales y deteniendo el proceso de consolidación urbana y de construcción del bien común, que era la característica tradicional de las organizaciones en los asentamientos.

En estos AAHH formalizados, a diferencia de los antiguos, una vez que obtienen los servicios básicos y la titularidad, la organización disminuye, desaparece o se transforma en organizaciones funcionales, como los Comedores Populares ${ }^{4}$ o el programa Vaso de Leche, ${ }^{5}$ dirigidas por mujeres. Estas organizaciones enfrentan serias acusaciones públicas vinculadas a que lucrarían con los víveres y la ayuda recibida del Estado, y darían el beneficio a personas que no lo necesitan. La organización vecinal está vigente porque es una imposición del proceso de formalización, ya que la PNF establece que la titulación debe ser un proceso colectivo, aunque el fin real sea la obtención del título de propiedad individual.

Respecto a la situación actual de la consolidación urbana en los AAHH formalizados, se registró en el trabajo de campo que los casos de estudio, en su totalidad, cuentan con servicios básicos, aunque con algunas limitaciones. Haciendo un balance, el valor de las propiedades ha aumentado considerablemente, en menor medida por los trabajos colectivos de los residentes, y mayoritariamente por la inversión estatal en mejoramiento del entorno urbano a escala metropolitana. Tal es el caso de los AAнH La Providencia y Villa Huanta con la construcción de la

4 Los comedores populares son programas del Estado monitoreados por las municipalidades distritales, destinados a entregar almuerzos a bajo costo, pues el Estado subsidia la mayoría de los ingredientes y los utensilios. Funcionan bajo la dirección de "clubes de madres", cuyas integrantes se organizan en turnos de cocina para atender a los miembros adscritos o "socios".

5 El "Vaso de Leche" es un programa del gobierno central, tutelado por el Ministerio de Desarrollo e Inclusión Social, creado en 1985. Consta en otorgar una ración diaria de leche o similar a niños entre 0 y 6 años, como primera prioridad, en pobreza o extrema pobreza. También se pueden inscribir al programa ancianos o enfermos de твC. Está monitoreado por las municipalidades distritales en coordinación con las organizaciones de madres. 
Línea 1 del Metro de Lima; y de 9 de Setiembre y 19 de Mayo por el corredor vial metropolitano y los parques zonales próximos.

La Municipalidad realmente no nos ayuda, a pesar de que estamos en el centro de Los Olivos. La Municipalidad no está en el centro, nosotros estamos en el centro de Los Olivos. Es por eso que el costo de los terrenos de acá se ha elevado tremendamente. Nos costó 176 soles [nuevos soles, equivalente a USD 50] un lote, ahora un lote de terreno te cuesta 180.000 dólares [USD] (Hugo, vecino del Asentamiento 19 de Mayo).

La plusvalía por el aumento exponencial del valor del suelo en estos AAHH solo beneficia al propietario, y el Estado pierde así una gran oportunidad de captar recursos para continuar con las mejoras. Es necesario mencionar también que existen centros urbanos creados por el capital privado, como centros comerciales o instituciones educativas, que dotan a los asentamientos de ciertos espacios de carácter semipúblicos, los cuales contribuyen a elevar el precio del suelo. A pesar de las mejoras visibles, los vecinos de todos los AAHH formalizados que fueron visitados mencionan que, en la realidad, ellos ya son urbanizaciones -lo cual los enorgullece-. Sin embargo, no cambian su categorización catastral, como lo explica Martín:

La realidad refleja otra cosa: "No, asentamiento no hay con cuatro pisos, con una emisora"; por eso la gente dice "si cambiamos de razón, los impuestos por un lado que se van a duplicar, duplicar el agua, todos los servicios; y por otro lado, cuando tú cambias, se sobrevalúan los predios un poco para los préstamos". O sea, tiene sus pros y sus contras, pero la gente siempre ve por el lado hacia ellos... (Vecino del Asentamiento Villa Huanta).

En suma, la mayor producción del espacio urbano en el AML es resultado de la acción de los habitantes de los AAHH, con muy poca ayuda estatal, donde la organización social se convirtió en el desarrollador urbano. El Estado solo ha servido como ente regulador y proveedor de servicios básicos, cuando ha sido posible. La planificación de la ciudad ha pasado a un segundo plano frente a la importancia que se la ha dado a la construcción física, pero sobre todo a la construcción de un patrimonio individual.

\section{Conclusiones}

La informalidad en el Perú -y específicamente en Lima- es un fenómeno multisectorial, cuya complejidad, a diferencia de lo que ocurre en otros países, dificulta y casi imposibilita distinguir la irregularidad de la ilegalidad. En términos de informalidad urbana, el panorama no es muy distinto al de otras ciudades de la región, pero en comparación con otros aspectos de la informalidad, la producción informal de ciudad se ve limitada debido a la escasez de suelo para la invasión. Dedicado solo a entregar y regularizar la tierra, la aparente inercia del aparato estatal frente a la informalidad urbana exacerba la producción de suelo urbano bajo esta modalidad. De igual manera, estas zonas aparentemente olvidadas por el Estado se han vuelto un público objetivo para las inversiones trasnacionales en el ámbito del 
retail, unidades comerciales que proporcionan crédito con facilidad a los habitantes de los AAHH. Esto aumenta la percepción de capacidad de pago de la población y, como consecuencia, se dota a estas zonas periféricas de centros comerciales a falta de espacio público para la recreación. Así se sustituye de alguna forma la presencia del Estado. En otras palabras, "el derecho a una vivienda digna" se ha sustituido por el "derecho a la propiedad" impulsada por la PNF, que -en palabras de Roy (2005) - en el contexto actual de acumulación de capital, sería el derecho a participar en los mercados inmobiliarios. Esto explica en parte por qué, a pesar de estas condiciones, los asentamientos no dejan de proliferar en la ciudad.

En la actualidad, los AAHH se reproducen no solo con fines de vivienda, sino como fuente de recursos económicos, validada por la economía informal del mercado ilegal de tierras, la permisividad estatal y la ideología de la propiedad privada impuesta por la PNF. Esto ocurre porque no existe un correcto control estatal del suelo y su función social de uso queda relegada frente a la titularidad del mismo, lo que ocasiona la especulación del suelo urbanizable y favorece a los urbanizadores piratas, tal como plantean Jaramillo (2008) y Calderón (2014). Esta nueva lógica de apropiación del suelo concuerda con lo que Abramo (2003) llama la "estructura híbrida de la ciudad", donde la lógica de la necesidad se articula con la lógica del mercado. La Lima informal vive cada día entre la crisis y la supervivencia. Hoy, uno de cada tres peruanos vive "en" y "de" la informalidad, convirtiendo la ciudad en un desafío constante por su complejidad de producción y estilos de vida asociados.

En término de planificación, y a pesar de las políticas de descentralización que rigen en el Perú, la inexistencia de una ley de suelo lleva a que la gestión local municipal no contemple ni la regulación ni la fiscalización de la producción del suelo urbano, lo que se presta para que los gobernantes puedan transar la tierra a cambio de réditos políticos, sin importar que esa tierra entregada sea vulnerable. Esto ocurre sobre todo en los ААНH no formalizados e informales, donde el riesgo frente a los fenómenos naturales es elevado, sobre todo en el caso de las remociones de tierra. Además, las condiciones geográficas complejizan las conexiones de servicios básicos, lo que aumenta la insalubridad y las enfermedades de niños y ancianos. Ninguna de estas situaciones es tomada en cuenta por los gobernantes a la hora de emitir la Constancia de Posesión a los nuevos AaHH.

Para la organización social, en cuanto desarrollador urbano tradicional de las barriadas, el aparente beneficio de orden legal y económico que propiciaba la PNF mermó su intensidad de organización e instauró la lógica de la propiedad privada por sobre el bien común. Es decir, convirtió la lucha colectiva por la vivienda y la urbanización en la lucha individual por la propiedad privada, privilegiando la construcción del patrimonio personal por sobre la urbanización de los asentamientos, aumentando con ello la fragmentación de la ciudad y las desigualdades sociales. Esta es la peor consecuencia de la PNF y su apuesta por la regulación masiva. Tal como plantea Calderón (2014), la PNF extinguió el valor de uso que le otorgaban los pobladores al terreno ocupado, para convertirlo en el derecho a la posesión de un lote, sin garantías de que sea realmente con fines de vivienda. La PNF ha generado "ciudadanos de segunda clase", ya que en el papel son ciudadanos peruanos con derecho a una vida digna, pero en la realidad son personas con un título de 
propiedad del suelo viviendo en condiciones de habitabilidad muy bajas y sin los beneficios de la ciudad, pues se encuentran muy apartados de las posibilidades que ofrece la Lima formal. La característica trasversal a ambos tipos de AAHH formalizados es que la organización social reniega del poco apoyo que sus integrantes recibieron y reciben del Estado para mejorar su condición urbana.

Siguiendo los planteamientos de Durston (2003), se puede concluir que sí existe un capital social de tipo comunitario, pues la participación es un derecho de todos los integrantes de las organizaciones sociales y existen mecanismos de democracia en la toma de decisiones. Sin embargo, por ahora es un capital social negativo, que está siendo cooptado por el Estado mediante lazos clientelares. Se trata este de un clientelismo pasivo, pues crea una dependencia entre la necesidad de los vecinos en cuanto a lograr la construcción de obras, y la voluntad política del gobernante. Es por esta relación que las organizaciones sociales naturalizan la corrupción y la informalidad.

En Lima, a pesar de ser una ciudad muy segregada, los inversionistas han podido valorizar su capital bajo distintas modalidades, relativas a los patrones de consumo de los diferentes estratos socioeconómicos. Por una parte, está la Lima que se alinea a los patrones comunes de las aglomeraciones de consumo bajo la lógica neoliberal; y por otra, está la otra Lima que, pese a estar marginada de los procesos globalizantes y de la economía formal, representa la característica del "neoliberalismo variopinto" (Brenner, 2009; De Mattos, 2014) peruano.

Por lo tanto, se puede concluir que, a pesar de que las zonas periurbanas de Lima se ven aparentemente marginadas de los efectos de la globalización per se, la tendencia a la expansión territorial urbana es inevitable. A falta de Estado, el capital privado inyecta capital suficiente para ampliar las condiciones de movilidad, así como el ingreso medio familiar, a través de la deuda, lo que conduce a la demanda por mayor consumo de tierra por habitante. Las brechas sociales se acrecientan, y más allá de las reconfiguraciones morfológicas, ello implica cambios fundamentales en la organización social y en el sentido mismo de la vida urbana. En concordancia con Calderón (2004, 2016), observamos que el predominio del bien individual por sobre el bien colectivo impulsado por las políticas neoliberales, se traduce en el espacio urbano en una competencia por el suelo como bien capitalizable en la construcción de un patrimonio individual, alterando con ello los procesos típicos de consolidación urbana de las barriadas impulsados por las organizaciones sociales. Esta nueva lógica de producción de ciudad obliga a repensar la epistemología de las bases de la planificación urbana, donde la informalidad como el "estado de excepción" se constituye en un paradigma generalizado. 


\section{Referencias bibliográficas}

Abramo, P. (2003). La teoría económica de la favela: cuatro notas sobre la localización residencial de los pobres y el mercado inmobiliario informal. Ciudad y Territorios: Estudios territoriales, 35(136-137), 273-294. http://habitat.aq.upm.es/boletin/n29/ apabr.html

Abramo, P. (2008). El mercado del suelo informal en favelas y la movilidad residencial de los pobres en las grandes metrópolis: un objeto de estudio para América Latina. Territorios, 18-19(1), 55-73. https://revistas.urosario.edu.co/index.php/territorios/ article/view/827

Alsayyad, N. \& Roy, A. (2006). Medieval Modernity: on citizenship and urbanism in a global era. Space and Polity, 1O(1), 1-20. https://doi.org/10.1080/13562570600796747

Atria, R. (2003). Capital social: concepto, dimensiones y estrategias para su desarrollo. En R. Atria, M. Siles, I. Arriagada, L. Robison \& S. Whiteford (eds.), Capital social y reducción de la pobreza en América Latina y el Caribe: en busca de un nuevo paradigma (pp. 581-590). Santiago, Chile: Comisión Económica para América Latina y el Caribe (Cepal).

Brenner, N. (2009). What is critical urban theory? City, 13(2-3), 198-207. https://doi. org/10.1080/13604810902996466

Brenner, N. \& Schmid, C. (2014). The 'urban age' in question. International Journal of Urban and Regional Research, 38(3), 731-755. https://doi.org/10.1111/1468-2427.12115

Calderón, J. (2004). La formalización de la propiedad en el Perú: Efectos económicos y socio culturales. Presentado en el Foro Electrónico Suelo: Acceso, regularización y precariedad urbana en América Latina y el Caribe. Santiago, Chile: Comisión Económica para América Latina y el Caribe (Cepal), División de Desarrollo Sostenible y Asentamientos Humanos. http://www.vivienda.mosp.gba.gov.ar/capacitacion/biblioclichevsky1.pdf

Calderón, J. (2014). Miradas, enfoques y estudios sobre las ciudades. Lima, Perú: Vicio Perpetuo.

Calderón, J. (2016). La ciudad ilegal. Lima, Perú: Punto Cardinal.

Clichevsky, N. (2003). Pobreza y acceso al suelo urbano. Algunas interrogantes sobre las politicas de regularización en América Latina. Santiago, Chile: Comisión Económica para América Latina y el Caribe (Cepal).

Clichevsky, N. (2009). Algunas reflexiones sobre informalidad y regularización del suelo urbano. Revista Bitácora Urbano Territorial, 14(1), 63-88. https://revistas.unal.edu.co/ index.php/bitacora/article/view/18508

Cofopri / Organismo de Formalización de la Propiedad Informal, Perú. Base de datos entregados por Ley de Transparencia, a solicitud de los investigadores.

De Mattos, C. (2014). Gobernanza neoliberal, financiarización y metamorfosis urbana en el siglo xxi. Documento de Trabajo, no publicado. https://flacso.edu.ec/cite/demattos-c_2014_gobernanza-neoliberal-financiarizacion-y-metamorfosis-urbana-enel-siglo-xxi/

De Soto, H. (1986). El otro Sendero: La revolución informal. Lima, Perú: Instituto Libertad y Democracia. 
Durston, J. (2003). Capital social: parte del problema, parte de la solución, su papel en la persistencia y en la superación de la pobreza en América Latina y el Caribe. En R. Atria, M. Siles, I. Arriagada, L. Robison \& S. Whiteford, Capital social y reducción de la pobreza en América Latina y el Caribe: en busca de un nuevo paradigma (pp. 147-202). Santiago, Chile: Comisión Económica para América Latina y el Caribe (Cepal).

Fernandes, E. (1999). Redefinición de los derechos de propiedad en la era de la liberalización y la privatización. En M. Smolka y L. Mullahy (eds.), Perspectivas urbanas: Temas críticos en politicas de suelo en América Latina (pp. 82-85). Boston, MA: Lincoln Institute of Land Policy.

Fernandes, E. (2008). Consideraciones generales sobre las políticas públicas de regularización de asentamientos informales en América Latina. EURE, 34(102), 25-38. http://dx.doi. org/10.4067/S0250-71612008000200002

Gilbert, A. (2001). La vivienda en América Latina. Serie de Documentos de Trabajo I-7UE/ Es. Instituto Interamericano para el Desarrollo Económico y Social (Indes), Banco Interamericano de Desarrollo. http://idbdocs.iadb.org/wsdocs/getdocument. aspx?docnum $=2220181$

Instituto Nacional de Estadística e Informática (INEI), Perú (2007). Censos Nacionales 2007: XI de Población y VI Vivienda. Lima, Perú: INEI. http://censos.inei.gob.pe/cpv2007/ tabulados/

Jaramillo, S. (2008). Reflexiones sobre la "informalidad" fundiaria como peculiaridad de los mercados del suelo en las ciudades de América Latina. Territorios, 18-19(1), 11-53. https://revistas.urosario.edu.co/index.php/territorios/article/view/826

Matos, J. (2012). Perú. Estado desbordado y sociedad emergente. Lima, Perú: Universidad Ricardo Palma, oficina editorial.

Mayer, M. (2003). The onward sweep of social capital: causes and consequences for understanding cities, communities and urban movements. International Journal of Urban and Regional Research, 27(1), 110-132. https://doi.org/10.1111/14682427.00435

Ministerio de Vivienda, Construcción y Saneamiento (mvcs), Dirección Nacional de Urbanismo (DNU), Perú. (2012). Situación de los Barrios Urbano-Marginales en el Perú 2012. Segunda aproximación. Lima: Mvcs.

Miraftab, F. (2009). Insurgent planning: situating radical planning in in the Global South. Planning Theory, 8(1), 32-50. https://doi.org/10.1177/1473095208099297

Municipalidad Metropolitana de Lima. Base de datos, a 2015, entregados por Ley de Transparencia, a solicitud de los investigadores.

Porter, L. (2011). Informality, the commons and the paradoxes for planning: concepts and debates for informality and planning. Planning Theory \& Practice, 12(1), 115-153. https://doi.org/10.1080/14649357.2011.545626

Roy, A. (2005). Urban informality. Toward an epistemology of planning. Journal of the American Planning Association, 71(2), 147-158. https://doi.org/10.1080/01944360508976689

Roy, A. (2011). Slumdog cities: rethinking subaltern urbanism. International Journal of Urban and Regional Research, 35(2), 223-238. https://doi.org/10.1111/j.14682427.2011.01051.x

Roy, A. \& Alsayyad, N. (2004). Urban informality: Transnational perspectives from the Middle East, Latin America and South Asia. Lanham, MD: Lexington Books. 
Torres, D. (2016). Lima: titulación de tierras sin ciudad, del bien colectivo al privado. La organización social como promotor urbano frente al fracaso de la Politica Nacional de Formalización (1996-2015). Tesis para optar al grado de Magíster en Desarrollo Urbano, Pontificia Universidad Católica de Chile.

Viana, I. (2007). Informalidad, regularización y derecho de propiedad. En M. Smolka \& L. Mullahy (eds.), Perspectivas urbanas: temas críticos en políticas de suelo en América Latina (pp. 66-70). Boston, MA: Lincoln Institute of Land Policy. 